\title{
Haploidentical related donor compared to HLA-identical donor transplantation for chemosensitive Hodgkin lymphoma patients
}

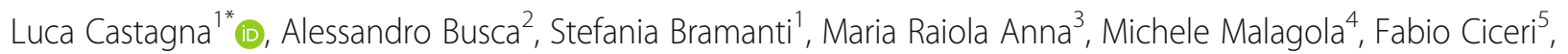
William Arcese ${ }^{6}$, Daniele Vallisa ${ }^{7}$, Francesca Patriarca ${ }^{8}$, Giorgina Specchia ${ }^{9}$, Roberto Raimondi ${ }^{10}$, Raynier Devillier ${ }^{11}$, Sabine Furst ${ }^{11}$, Laura Giordano ${ }^{12}$, Barbara Sarina ${ }^{1}$, Jacopo Mariotti ${ }^{1}$, Attilio Olivieri ${ }^{13}$, Reda Bouabdallah ${ }^{14}$, Carmelo Carlo-Stella ${ }^{1}$, Alessandro Rambaldi ${ }^{15}$, Armando Santoro ${ }^{1}$, Paolo Corradini ${ }^{16}$, Andrea Bacigalupo ${ }^{17}$, Francesca Bonifazi ${ }^{18}$ and Didier Blaise ${ }^{11}$

\begin{abstract}
Background: Allogeneic stem cell transplantation from haploidentical donor using an unmanipulated graft and post-transplantation cyclophosphamide (PT-Cy) is growing. Haploidentical transplantation with PT-Cy showed a major activity in Hodgkin lymphoma $(\mathrm{HL})$, reducing the relapse incidence. The most important predictive factor of survival and toxicity was disease status before transplantation, which was better in patients with well controlled disease.
\end{abstract}

Methods: We included $198 \mathrm{HL}$ in complete (CR) or partial remission (PR) before transplantation. Sixty-five patients were transplanted from haploidentical donor and 133 from a HLA identical donor (both sibling and unrelated donors). Survival analysis was defined according to the EBMT criteria. Survival curves were generated by using Kaplan-Meier method and differences between groups were compared by the log rank test or by the log rank test for trend when appropriated.

Results: The PFS, OS, and RI were significantly better in patients in CR compared to PR (55\% vs 29\% $p=0.001,74 \%$ vs $55 \% p=0.03,27 \%$ vs $55 \% p<0.001$, respectively). The 2-year PFS was significantly better for HAPLO than HLA-id (63\% vs 37\%, $p=0.03$ ), without difference in OS. The 1-year NRM was not different. The 2-year relapse incidence (RI) was lower in the HAPLO group ( $24 \%$ vs $44 \%, p=0.008$ ). Patients in CR receiving haplo HSCT showed higher 2-year PFS and lower 2-year RI than those allografted with HLA-id donor (75\% vs 47\%, $p<0.001$ and $11 \%$ vs 34\%, $p<$ 0.001 , respectively). In multivariate analysis, donor type and disease status before transplantation were independent predictors of PFS as well as they predict the risk of relapse. Disease status at transplantation and age were independently associated to OS.

(Continued on next page)

\footnotetext{
* Correspondence: Icastagna63@gmail.com

'Humanitas Cancer Center, BMT Unit, Humanitas Research Hospital, IRCCS, Via Manzoni 56, Rozzano, Ml, Italy

Full list of author information is available at the end of the article
}

C C The Author(s). 2020 Open Access This article is licensed under a Creative Commons Attribution 4.0 International License, which permits use, sharing, adaptation, distribution and reproduction in any medium or format, as long as you give appropriate credit to the original author(s) and the source, provide a link to the Creative Commons licence, and indicate if changes were made. The images or other third party material in this article are included in the article's Creative Commons licence, unless indicated otherwise in a credit line to the material. If material is not included in the article's Creative Commons licence and your intended use is not permitted by statutory regulation or exceeds the permitted use, you will need to obtain permission directly from the copyright holder. To view a copy of this licence, visit http://creativecommons.org/licenses/by/4.0/ The Creative Commons Public Domain Dedication waiver (http://creativecommons.org/publicdomain/zero/1.0/) applies to the data made available in this article, unless otherwise stated in a credit line to the data. 
(Continued from previous page)

Conclusions: Nonetheless this is a retrospective study, limiting the wide applicability of results, data from this analysis suggest that HLA mismatch can induce a strong graft versus lymphoma effect leading to an enhanced PFS.

Keywords: Haploidentical transplantation, Hodgkin lymphoma, Reduced intensity conditioning regimen

\section{Background}

Allogeneic hematopoietic stem cell transplantation (alloHSCT) represents a potential curative option for patients with relapsed or refractory Hodgkin's lymphoma (HL) [15], and has shown to be offer a survival advantage, over chemotherapy alone, for patients relapsing after an autologous transplant [4]. However, an HLA-identical related or unrelated donor is available only for a subset of patients, and family mismatched donors are warranted for such patients. The Baltimore group has shown that $\mathrm{T}$ cell-replete haploidentical transplantation, is feasible following a nonmyeloablative conditioning regimen (NMAC) and posttransplant cyclophosphamide (PT-Cy), with a good toxicity profile [6]. In a retrospective study on patients with $\mathrm{HL}$, the relapse risk was decreased in patients grafted from a haploidentical (HAPLO) donor, compared patients grafted from HLA identical sibling (SIBS) or unrelated donors (UD), with a 2-year progression-free survival (PFS), of $51 \%$ for HAPLO versus $23 \%$ for SIBS and $29 \%$ for UD donors [7]. These results suggested a peculiar immunological graft-versus tumor effect of HAPLO donors against HL cells [8-10].

Recently, lymphoma patients grafted with HAPLO donors (using the Baltimore platform) was compared with patients grafted with SIBS or matched unrelated donor (MUD), in 3 registry based studies [11-13]. These studies showed comparable outcome, with a lower incidence of chronic GVHD after HAPLO grafts. The EBMT study, focusing on $\mathrm{HL}$, also showed comparable outcome, but included chemosensitive and chemorefractory patients. We hypothesized that chemosensitive HL patients would be best suited to test whether HAPLO donors would induce a stronger graft versus lymphoma effect, as compared to SIBS and UD. We are now reporting a comparative analysis of 198 patients with HL with chemosensitive disease receiving allo-HSCT from SIBS/ MUD, or HAPLO donor.

\section{Methods}

In this analysis we included HL patients receiving haploHSCT, in 3 Centers (Humanitas Research Hospital, Rozzano; Ospedale San Martino, Genova; Institut Paoli Calmettes, Marseille, France) and HL patients receiving, during the same period (from 2009 to 2012), a HLA identical transplantation, both from related or unrelated donor, selected by centers from the Gruppo Italiano Trapianto di Midollo e cellule staminali periferiche
(GITMO). This retrospective study was approved by ethical committee (ONC/OSS 04/2015).

Search for allogeneic stem cell donor was initiated for patients relapsing after high-dose chemotherapy or requiring three or more chemotherapy lines to control initial disease, or in case of disease refractory to salvage chemotherapy. For patients lacking an HLA-id sib or UD, haploidentical donor was searched.

We analyzed if the survival was different between HLAid and MUD, and the 2-year PFS and OS were not statistically different (HLAid vs MUD, 2-y PFS 28 vs $38 \%$ (p 0.47); 2 -y OS $73 \%$ vs 53\% (p 0.087), allowing us to combine them.

\section{Inclusion criteria}

We included only chemosensitive (complete remission, CR or partial remission, PR) patients before allo-HSCT, performed during the same time frame (from 2010 and 2014): 65 patients received haploidentical transplantation (HaploHSCT) and 133 HLA-identical (HLA-id) transplantation, both from sibling and unrelated donors. The institutional review board of each center approved the study.

\section{Haploidentical transplantation}

Patients were conditioned using nonmyeloblative conditioning regimen including Cy $14.5 \mathrm{mg} / \mathrm{kg}$ on days -5 and -6 , fludarabine $30 \mathrm{mg} / \mathrm{m}^{2}$ from day -6 to day -2 and low-dose TBI (2 Gy) on day - 1. RIC regimen was used in one patient associating consisting of thiotepa $10 \mathrm{mg} / \mathrm{kg}$, fludarabine $30 \mathrm{mg} / \mathrm{m}^{2}$, and cyclophosphamide $30 \mathrm{mg} / \mathrm{kg}$. GVHD prophylaxis consisted of Cy $50 \mathrm{mg} / \mathrm{kg}$ administered on days +3 and +4 . On day +5 , tacrolimus or cyclosporine A (CyA) and mycophenolate mofetil (MMF) were started. Tacrolimus (FK 506, at a total dose of $1 \mathrm{mg}$ ) was administered as a continuous infusion until discharge and was converted to an oral formulation thereafter. The doses were adjusted to obtain serum levels between 10 and 20 $\mathrm{ng} / \mathrm{ml}$. CyA was dosed at $3 \mathrm{mg} / \mathrm{kg}$ as a continuous infusion until discharge and was converted to an oral formulation thereafter. The CyA doses were modified to obtain serum levels between 100 and $200 \mathrm{ng} / \mathrm{ml}$. MMF was administered at $15 \mathrm{mg} / \mathrm{kg}$ po three times per day until day +35 . G-CSF was started on day +5 in all the patients.

\section{HLA identical transplantation}

We will consider together patients grafted from identical siblings, and patients grafted from 8/8 matched 
unrelated donors, and we will refer to these as HLA identical transplants. Several reduced conditioning regimens were used for patients grafted from HLA identical donors, mostly including thiotepa. GVHD prophylaxis consisted of CyA and methotrexate (day $+1,+3,+6$, $+/-11$ ), combined with Thymoglobuline for UD transplants.

\section{Stem cell sources and donors}

In case of haploidentical transplantation, potential donors were typed at the HLA-A, HLA-B, HLA-C, HLADRB1, and HLA-DQB1 at a high resolution level. All the donor/recipient pairs exhibited a median of 4 mismatches (range 2-5) on the unshared haplotype. The donors underwent bone marrow harvest under general anesthesia, and the target dose was $4 \times 10^{8}$ nuclear cells/ $\mathrm{kg}$ of recipient weight. In Marseille, 20 donors underwent BM harvest, while 23 were mobilized by the subcutaneous administration of G-CSF (5 to 6 days at $10 \mu \mathrm{g} / \mathrm{kg} /$ day). The target yield was $4 \times 10^{6} \mathrm{CD} 34 / \mathrm{kg}$. Unmanipulated stem cells were infused on day 0 .

\section{Supportive care}

Each center applied specific supportive care in terms of antimicrobial prophylaxis and transfusion policies.

\section{Statistical analysis}

The aims of this study were to evaluate the impact of donor and disease status on outcome of allo-HSCT in HL patients.

Patients were compared with respect to the main clinical pathological characteristics: gender, age, number of previous lines of therapy, therapeutic program, disease status at transplant, CMV, ATG and conditioning regimens. Differences between groups were evaluated by using the T-test for continuous distributions and the Chi-square or the Fischer exact test for categorical distributions.

Survival analysis was defined according to the EBMT criteria. Progression free survival (PFS), relapse incidence (RI), overall survival (OS) and non-relapse mortality (NRM) were evaluated starting time from allogeneic transplantation. Cumulative incidence was considered to estimate aGVHD, cGVHD, relapse incidence (RI) and non-relapse mortality (NRM) after haploidentical transplantation. Survival curves were generated by using Kaplan-Meier method and differences between groups were compared by the log rank test or by the log rank test for trend when appropriated. To test whether the differences in cumulative incidence were statistically significant the Gray's method was applied. All analysis were performed using Stata 13 and R 3.0.3 softwares.

\section{Results}

Patient and transplantation characteristics are reported in Table 1. The median time of observation for surviving patients was 29 months (range 14.1-57.4), with no difference between haplo and HLAid.

\section{Engraftment}

In the HAPLO group, the median time to reach an ANC of more than $0.5 \times 10^{\wedge} \mathrm{g} / \mathrm{L}$, was 20 days (range 14-32), and in the HLAid group 14 days (range 7-47). Failure to engraft was seen in 3 HAPLO patients (7\%) and in 2 patients $(6 \%)$ in the HLAid group. In the haplo group, 2 out 3 patients had graft failure because of donor specific antibodies (DSA), and 1 patient died of pneumonia before engraftment.

\section{Acute and chronic GVHD}

In the HAPLO and HLA-id group, the incidence of grade $2-4$ acute GVHD was $15 \%$ vs $16 \%(p=0.9)$ and chronic GVHD were $18 \%$ vs $32 \%(p=0.06)$, respectively.

\section{Survival, relapse and NRM (Table 2)}

The overall 2-year PFS, OS, relapse incidence (RI), and $1 y$-NRM were $45,66,38$, and $14 \%$, respectively. The PFS, OS, and RI were significantly better in patients in CR compared to those in PR (55\% vs $29 \% p=0.001,74 \%$ vs $55 \% p=0.03,27 \%$ vs $55 \% p<0.001$, respectively. (Figs. 1a, b, 2a), whereas the 1-year NRM was similar $(15 \%$ vs $16 \% p=0.9)$.

The 2-year PFS for HAPLO and HLA-id HSCT, was $63 \%$ vs $37 \%(p=0.03)$ (Fig. $1 c)$, the 2 -year OS $67 \%$ vs $63 \%(p=0.6)$ (Fig. 1d), and the 1-year NRM was $13 \%$ vs $15 \%,(p=0.9)$, respectively. The 2-year RI was significantly lower in the HAPLO group $(24 \%$ vs $44 \%, p=$ 0.008) (Fig. 2b).

We analyzed the clinical outcome in specific subgroups of patients, combining disease status and donor. As shown in Table 2, patients in CR receiving a haplo HSCT showed a significantly better 2-year PFS (Fig. 1e) and lower 2-year RI (Fig. 2c) compared to those allografted with HLA-id donor (75\% vs $47 \%, p<0.001$ and $11 \%$ vs $34 \%, p<0.001$, respectively). No statistically significant differences were founded in terms of OS (Fig. $1 \mathrm{~g}$ ) and NRM. In PR patients, we found a similar advantage for HAPLO donors with a 2 -year PFS of $44 \%$ vs $22 \%, p<0.001$ (Fig. 1e); and the 2 -year RI was $44 \%$ vs $60 \%, p<0.001$ (Fig. 2c). Finally, patients in PR receiving transplantation from a HLAid donor showed the worst outcome in terms of PFS and RI (22 and 60\%, respectively) (Figs. 1e and 2c).

\section{Univariate and multivariate analysis (Table 3)}

In univariate analysis, age (with a cut off at 45 years), recipient CMV serostatus, ATG, conditioning regimen, 
Table 1 Patient and transplantation characteristics

\begin{tabular}{|c|c|c|c|c|}
\hline & $\begin{array}{l}\text { All pts. } \\
N=198\end{array}$ & $\begin{array}{l}\text { HLAid } \\
N=133\end{array}$ & $\begin{array}{l}\text { Haplo } \\
N=65\end{array}$ & $p$ \\
\hline Age, years (median, range) & $32(18-66)$ & $32(18-65)$ & $31(18-65)$ & 0.8 \\
\hline Sex M/F & $113 / 85$ & $77 / 56$ & $36 / 29$ & 0.7 \\
\hline Number of CT lines (median, range) & $2(2-12)$ & $2(2-9)$ & $4(2-12)$ & $<0.001$ \\
\hline Previous HDC & 170/198 (86\%) & 110/133 (83\%) & $60 / 65(92 \%)$ & 0.007 \\
\hline \multicolumn{5}{|l|}{ Disease status at transplantation } \\
\hline$C R$ & $119(60 \%)$ & $82(62 \%)$ & $37(60 \%)$ & \\
\hline$P R$ & $79(40 \%)$ & $51(38 \%)$ & $28(40 \%)$ & \\
\hline Donors & & & & NA \\
\hline HLA sibling & / & $57(43 \%)$ & / & \\
\hline MUD & / & $76(57 \%)$ & / & \\
\hline Haplo & / & / & 65 & \\
\hline \multicolumn{5}{|l|}{ Stem cell source } \\
\hline PBSC & $134(60 \%)$ & $114(83 \%)$ & $20(31 \%)$ & $<0.001$ \\
\hline BM & $63(31 \%)$ & $18(13 \%)$ & $45(69 \%)$ & \\
\hline miss & $1(9 \%)$ & $1(4 \%)$ & / & \\
\hline ATG prophylaxis GVHD & & & & NA \\
\hline No & $122(62 \%)$ & $57(43 \%)$ & / & \\
\hline Yes & 76 (38\%) & $76(57 \%)$ & / & \\
\hline \multicolumn{5}{|l|}{ Conditioning regimens } \\
\hline NMAC & $58(29 \%)$ & $2(2 \%)$ & $58(89 \%)$ & $<0.001$ \\
\hline RIC & 101 (51\%) & $92(69 \%)$ & $7(11 \%)$ & \\
\hline MAC & $39(20 \%)$ & $39(29 \%)$ & / & \\
\hline
\end{tabular}

therapeutic program (relapse post-HDC), and disease status (CR vs PR) did not affect survival. Donor type (HAPLO vs HLA-id) influenced the PFS $(p=0.06)$, but not the OS. In multivariate analysis, donor type (haplo vs HLA-id HR 0.51, $p<0.001)$ and disease status before transplantation (CR vs PR HR 0.37, $p=0.014$ ) were independent predictors of PFS as well as they predict the risk of relapse (donor type HR 0.37, $p<0.001$; disease status, HR 0.43, $p=0.006$ ). Disease status at transplantation and age (as continuous variable) were independently associated to OS (CR vs PR HR 0.57, $p=0.02$; age HR 0.04, $p=0.006)$.

\section{Discussion}

In this study, we have tested the effect of donor type on outcome, in chemosensitive HL patients, undergoing an allogeneic transplant from haploidentical donor, using a

Table 2 Main outcomes in all patients and specific sub-groups

\begin{tabular}{|c|c|c|c|c|c|c|c|c|c|}
\hline & $\mathbf{N}$ & 2y PFS & $p$ & $2 y O S$ & $p$ & $2 y R I$ & $p$ & 1y NRM & $p$ \\
\hline All & 18 & $45 \%$ & & $66 \%$ & & $38 \%$ & & $14 \%$ & \\
\hline CR vs $P R$ & 119 vs 79 & $55 \%$ vs $29 \%$ & 0.001 & $74 \%$ vs $55 \%$ & 0.03 & $27 \%$ vs $55 \%$ & $<0.001$ & $13 \%$ vs $16 \%$ & 0.8 \\
\hline Haplo vs HLAid & 65 vs 133 & $63 \%$ vs $37 \%$ & 0.03 & $67 \%$ vs $63 \%$ & 0.6 & $24 \%$ vs $44 \%$ & 0.008 & $13 \%$ vs $15 \%$ & 0.9 \\
\hline CR Haplo vs & 37 & $75 \%$ & $<0.001^{a}$ & $83 \%$ & 0.1 & $6 \%$ & $<$ & $14 \%$ & 0.8 \\
\hline CR HLAid vs & 82 & $47 \%$ & & $67 \%$ & & $34 \%$ & $0.001^{a}$ & $13 \%$ & \\
\hline PR Haplo vs & 28 & $44 \%$ & & $58 \%$ & & $44 \%$ & & $11 \%$ & \\
\hline PR HLAid & 51 & $22 \%$ & & $54 \%$ & & $60 \%$ & & $18 \%$ & \\
\hline
\end{tabular}


a
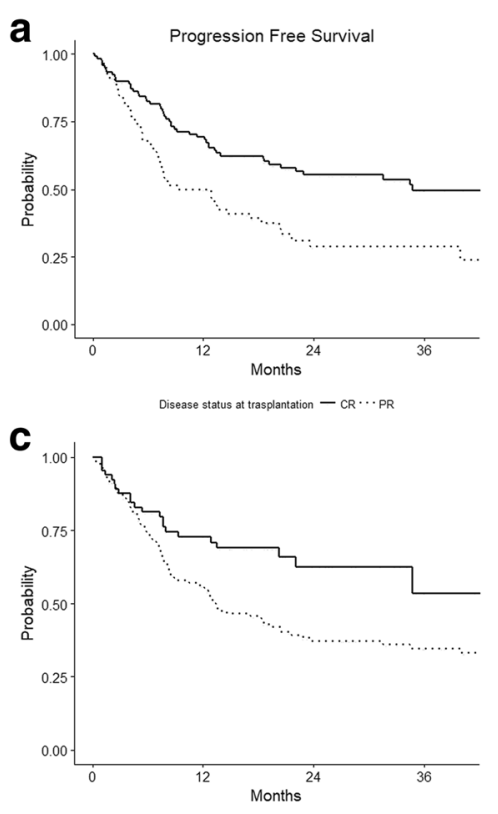

e

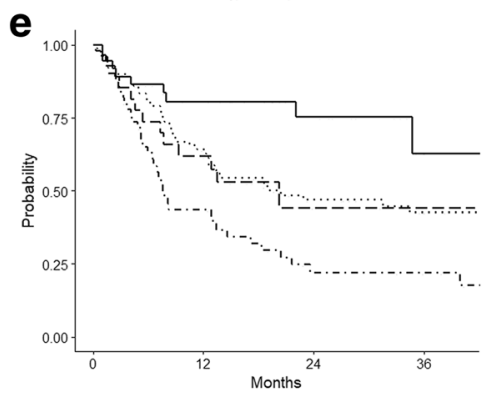

Combined - Haplo CR $\cdots$ Haplo PR - HLA.d CR $\cdots$ HLA-A PR

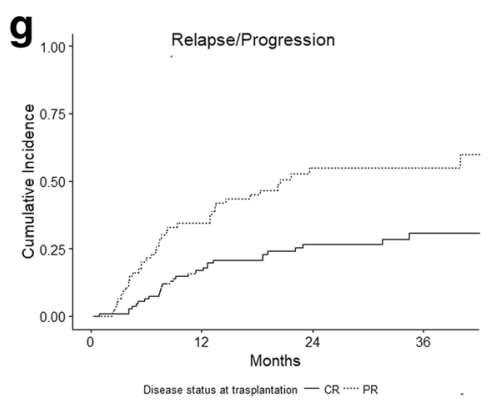

i

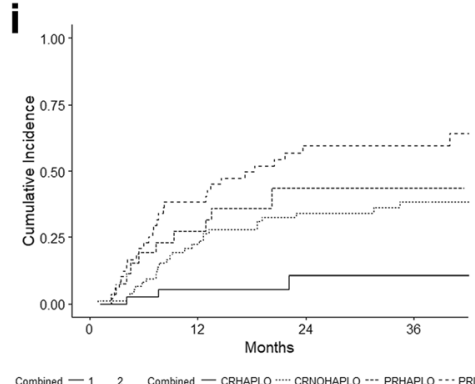

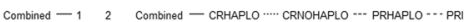
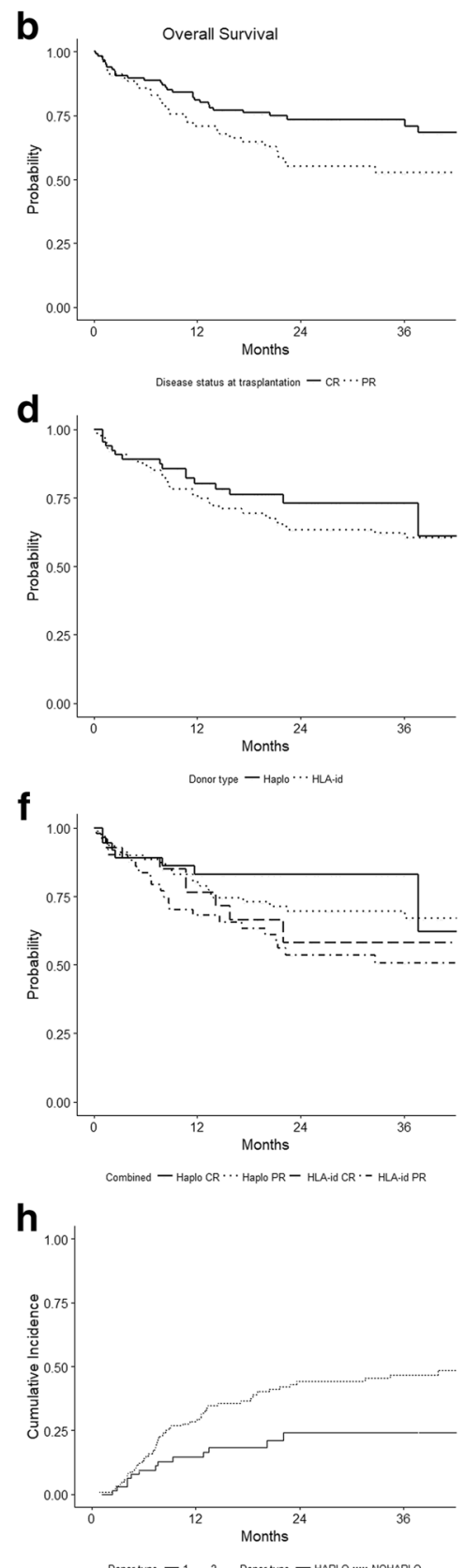

Donor type $-1 \quad 2$ Donortype - HAPLO -.... NOHAPLO

Fig. 1 PFS by disease status (a), donor type (c), and combining disease status and donor type (e), OS by disease status (b), donor type (d), and combining disease status and donor type $(\mathbf{g})$ 


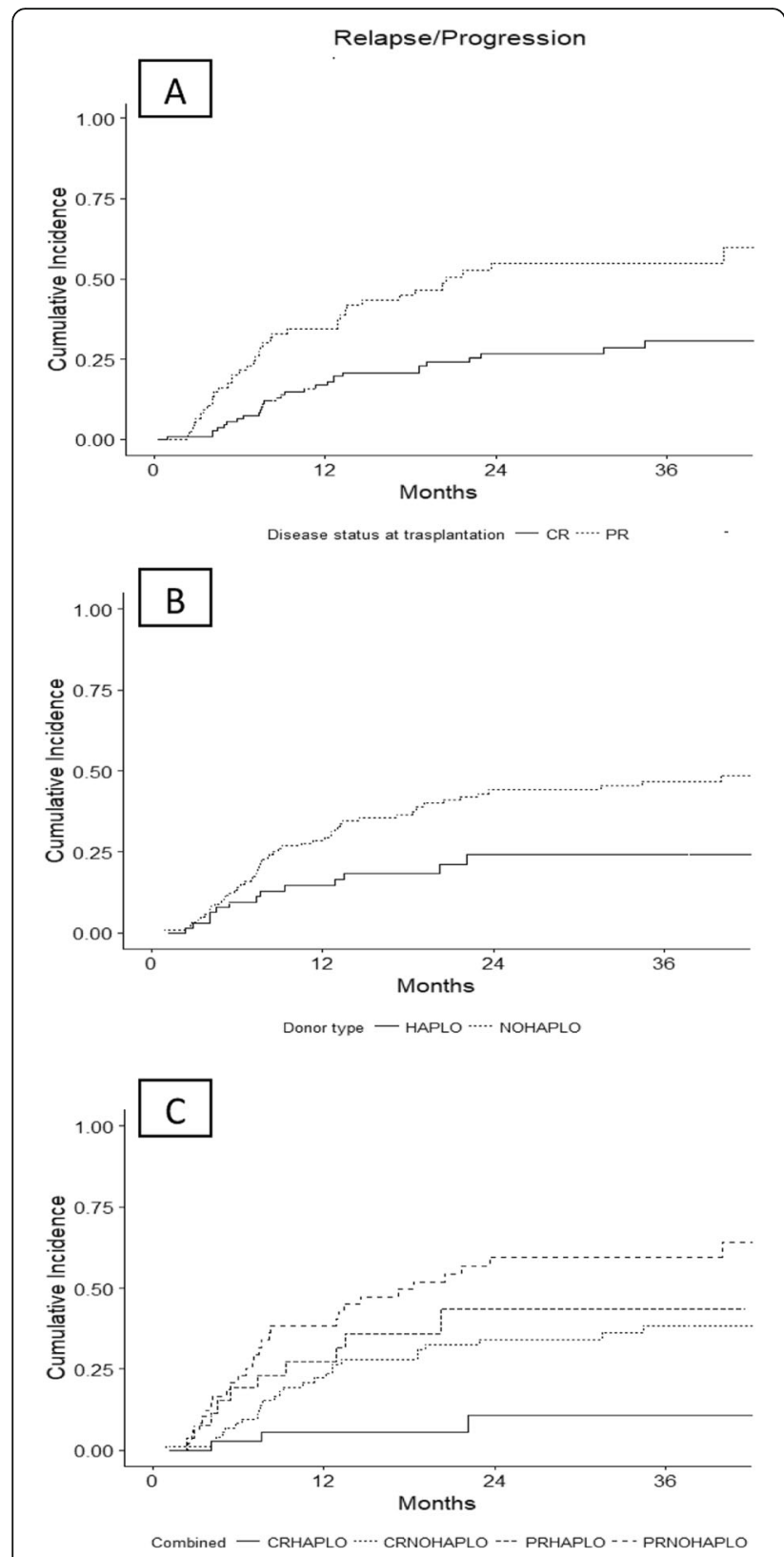

Fig. 2 Relapse incidence by disease status (a), donor type (b), and both $(\mathbf{c})$

T-replete stem cell source and PT-Cy, or HLA identical donors, which included matched siblings and matched unrelated donors.

We have shown that, haplo-HSCT result in a significantly superior 2-year PFS (63\%), when compared to HLA identical transplants (37\%). This is due to a significantly reduced risk of relapse in HAPLO patients: the 2year cumulative incidence of relapse was indeed $24 \%$ for HAPLO and $44 \%$ for HLA identical grafts. This was seen despite the fact that HAPLO patients were all prepared
Table 3 Multivariate analysis

\begin{tabular}{lll}
\hline & HR (Cl95\%) & P value \\
\hline PFS & $0.51(0.34-0.75)$ & $<0.001$ \\
$\begin{array}{l}\text { Disease status (CR vS PR) } \\
\text { Haplo vs HLAid }\end{array}$ & $0.56(0.35-0.89)$ & 0.014 \\
OS & $0.57(0.35-0.93)$ & 0.023 \\
$\quad$ Disease status (CR vs PR) & $0.04(1.00-1.05)$ & 0.043 \\
$\quad$ Age (continuous variable) & & \\
Relapse & $0.37(0.23-0.60)$ & $<0.001$ \\
$\quad$ Haplo vs HLAid & $0.43(0.43-0.79)$ & 0.006 \\
\hline Disease status (CR vs PR)
\end{tabular}

$C R$ complete remission, $P R$ partial remission, $P F S$ progression free survival, $O S$ overall survival

with a non myeloablative, extremely mild conditioning regimen, whereas a proportion of patients in the HLA identical cohort received a more intensive regimen, recently shown to have a role in reducing tumor burden in HL [14].

Remission status remained significant prognostic variable in univariate and multivariate analysis, with CR patients having superior outcome as compared to partial remission patients, in keeping with data in the literature. When combining donor type and disease status, 37 HAPLO grafts in CR had the best 2 year PFS (75\%), with the lowest risk of relapse (6\%). HLA identical grafts in CR patients $(n=82)$ and HAPLO grafts in PR $(n=28)$ had quite comparable outcome, with a PFS of 47 and $44 \%$, and a risk of relapse of 34 and $44 \%$ respectively. The worst outcome was in 51 patients in PR grafted from HLA identical donors (22\% PFS and 60\% relapse). This was confirmed in a multivariate analysis on PFS and relapse, showing that donor type and remission status were independent predictors.

Overall survival was predicted only by disease status and patients age, but not by donor type: this is due to the fact that non relapse mortality was similar in patients grafted from HAPLO and HLA identical donors, whereas is was influenced by disease status and age, In addition post-transplant relapse can be rescued in HL patients $[15,16]$, and therefore a strong effect on relapse does not necessarily translate on survival, at least in the short/medium term.

Another important point was the toxicity of haploidentical transplantation: both in CR and PR groups, the 1 -year NRM was low and not different as summarized in Table 2. Similarly, the incidence of grade 2-4 aGVHD was similar, despite the fact that $31 \%$ of HAPLO grafts were performed using peripheral stem cells. Chronic GVHD in the haplo group was in line with previous reports, and basically lower compared to that observed in HLAid group. 
These results challenge those reported in other comparative studies from CIBMTR, including Hodgkin and non-Hodgkin lymphomas, and one study from the EBMT on HD patients only. The CIBMTR study compared 44 patients grafted from haploidentical donors, to 178 patients transplanted from a matched related donor [11]. They found no difference in terms of 3-year PFS and RI ( $48 \%$ vs 48 and $37 \%$ vs $40 \%$, respectively). In the second CIBMTR study, haploidentical transplants were compared to patients grafted from matched unrelated donor. Again, no differences were observed in terms of PFS and RI [12]. The recent EBMT study included HL patients only and again the survival, NRM and aGVHD incidence were similar between haplo-HSCT, matched related donor and matched unrelated donor [13]. Other studies from French Society of transplantation showed similar results [14]. The question is why our present study would instead show an advantage for HL patients receiving a HAPLO graft: one possibility is the inclusion criteria, since we enrolled exclusively patient with chemosensitive disease, whereas in the previous studies the percentage of refractory patients was consistent (ranging from 5 to 30\%) [11-14]. Relapse rates are very high in chemoresistant patients, also after an allogeneic transplant, and this may quench the beneficial effect of given donor type.

But why should HAPLO grafts have a stronger graft versus HL effect? We hypothesize two possibilities. In the first place donor lymphocytes may interact more effectively with Hodgkin's cellular microenvironment, inducing apoptosis, and indirectly affecting survival of Reed Sternberg cells [17]. The second possibility comes from a recent study on check-point inhibitor activity against HL: in this study, the activity of check-point inhibitors was higher when HL cells expressed HLA class II molecules [18]. We speculate that class II HLA mismatches in a HAPLO transplant, may enhance the antitumoral effect of donor CD4+ T cells.

The present study has several and important limitations, mainly due to its retrospective nature, such that we cannot exclude some bias in patient's selection. The use of haploidentical transplantation started in 2010, therefore patients with an indication of HSCT and without a HLA-id donor before that date did not undergo an allogeneic HSCT. In addition, GvHD prophylaxis was different, based on PTCY in the HAPLO patients and on ATG in the HLA identical grafts, although in a previous analysis, ATG did not significantly influence the outcome in lymphoma patients receiving allogeneic stem cell transplantation [10]. Finally, the conditioning regimen was the same for all HAPLO patients and rather heterogeneous in the HLA identical group, although there is little evidence in the literature that conditioning regimens influence the outcome of allogeneic HSCT in HL patients [19].

\section{Conclusions}

This study suggests that HLA haploidentical transplantation, using T-cell replete stem cells and PT-Cy, is more effective than HLA identical grafts in chemosensitive advanced $\mathrm{HL}$, due to greater antitumor activity, challenging the question of donor choice. A prospective comparative study is needed, possibly using the same conditioning regimen and the same prophylaxis for graft versus host disease, in order to assess the role of HLA haploidentical grafts for patients with Hodgkin lymphoma.

\section{Abbreviations}

HL: Hodgkin lymphoma; CR: Complete remission; PR: Partial remission; PFS: Progression free survival; OS: Overall survival; RI: Relapse incidence; NRM: No relapse mortality; allo-HSCT: Allogeneic hematopoietic stem cell transplantation; NMAC: Nonmyeloablative conditioning regimen; PT-Cy: Posttransplant cyclophosphamide; SIBS: HLA identical sibling; UD: Unrelated donor; HAPLO: Haploidentical; CyA: Cyclosporine A; MMF: Mycophenolate mofetil; FK 506: Tacrolimus; GVHD: Graft versus host disease

\section{Acknowledgements}

We would thank Leo Luznik for the support and for useful comments on the paper.

We would thank the GITMO centers including patients in this analysis.

\section{Authors' contributions}

$C L, B A 2, B D, C P, B F, R A$ designed the study. $C L, B A 2, B D$ wrote the paper. $C L$, $B A 1, B S, R A M, M M, C F, A W, V D, P F, S G, R R, D R, F S, S B, M J, O A, B R, C C S, R A$, $\mathrm{SA}, \mathrm{CP}, \mathrm{BA} 2, \mathrm{BF}, \mathrm{BD}$ provided patients and approved the manuscript. $\mathrm{GL}$ performed statistical analysis. All authors have read and approved the manuscript.

\section{Funding}

Not applicable.

\section{Availability of data and materials}

The datasets used and/or analyzed during the current study are available from the corresponding author on reasonable request.

\section{Ethics approval and consent to participate}

This retrospective study was approved by ethical committee (ONC/OSS 4/ 2015)

\section{Consent for publication}

Not applicable.

\section{Competing interests}

The authors declare no competing financial interests.

\section{Author details}

${ }^{1}$ Humanitas Cancer Center, BMT Unit, Humanitas Research Hospital, IRCCS, Via Manzoni 56, Rozzano, MI, Italy. ${ }^{2}$ Hematology Department Azienda ospedaliera Universitaria S Giovanni Battista, Torino, Italy. ${ }^{3}$ Division of Hematology and Hematopoietic Stem Cell Transplantation Unit, Ospedale Policlinico San Martino-IRCCS per I'Oncologia, Genoa, Italy. ${ }^{4}$ Department of Clinical and Experimental Sciences, Unit of Blood Diseases and Stem Cells Transplantation, ASST Spedali Civili of Brescia, University of Brescia, Brescia, Italy. ${ }^{5}$ Hematology and BMT Unit, Ospedale S Raffaele, Milan, Italy.

${ }^{6}$ Department of Hematology, Stem Cell Transplant Unit, Rome Transplant Network, "Tor Vergata" University Hospital, Rome, Italy. ${ }^{7}$ Hematology Department, Ospedale Gda Saliceto di Piacenza, Piacenza, Italy. ${ }^{8}$ Hematology, Department of Medical Area, University of Udine, Udine, Italy. ${ }^{9}$ Hematology Section, DAP University of Bari, Bari, Italy. ${ }^{10}$ Hematology Department, S. Bortolo Hospital, Vicenza, Italy. ${ }^{11}$ Hematology Department, Transplantation and Cellular Therapy Unit, Institut Paoli-Calmettes, Marseille, France.

${ }^{12}$ Humanitas Cancer Center, Statistical Unit, Humanitas Research Hospital, Rozzano, Italy. ${ }^{13}$ Department of Hematology, Medical School, University of Ancona, Ancona, Italy. ${ }^{14}$ Hematology Department, Lymphoma Program, 
Institut Paoli-Calmettes, Marseille, France. ${ }^{15}$ Hematology and Bone Marrow Transplant Unit, Azienda Ospedaliera Papa Giovanni XXIII, Bergamo, Italy. ${ }^{16}$ Hematology and Bone Marrow Transplant Unit, Fondazione IRCCS Istituto Nazionale Tumori and University of Milano, Milan, Italy. ${ }^{17}$ Istituto di Ematologia, Università Cattolica del Sacro Cuore, Fondazione Policlinico Universitario Gemelli, Rome, Italy. ${ }^{18}$ Institute of Hematology and Medical Oncology, L and A Seràgnoli, St Orsola-Malpighi Hospital, University of Bologna, Bologna, Italy.

Received: 18 May 2020 Accepted: 30 October 2020

Published online: 24 November 2020

\section{References}

1. Thomson KJ, Peggs KS, Smith P, Cavet J, Hunter A, Parker A, et al. Superiority of reduced-intensity allogeneic transplantation over conventional treatment for relapse of Hodgkin's lymphoma following autologous stem cell transplantation. Bone Marrow Transplant. 2008;41:9.

2. Castagna L, Sarina B, Todisco E, Magagnoli M, Balzarotti M, Bramanti S, et al. Allogeneic stem cell transplantation compared with chemotherapy for poor-risk Hodgkin lymphoma. Biol Blood Marrow Transplant. 2009;15:4.

3. Robinson SP, Sureda A, Canals C, Russell N, Caballero D, Bacigalupo A, et al. Reduced intensity conditioning allogeneic stem cell transplantation for Hodgkin's lymphoma: identification of prognostic factors predicting outcome. Haematologica. 2009;94:2

4. Sarina B, Castagna L, Farina L, Patriarca F, Benedetti F, Carella AM, et al. Allogeneic transplantation improves the overall and progression-free survival of Hodgkin lymphoma patients relapsing after autologous transplantation: a retrospective study based on the time of HLA typing and donor availability. Blood. 2010;115:18.

5. Sureda A, Canals C, Arranz R, Caballero D, Ribera JM, Brune M, et al. Allogeneic stem cell transplantation after reduced intensity conditioning in patients with relapsed or refractory Hodgkin's lymphoma. Results of the HDR-ALLO study-a prospective clinical trial by the Grupo Español de Linfomas/Trasplante de Médula Osea (GEL/TAMO) and the Lymphoma Working Party of the European Group for Blood and Marrow Transplantation. Haematologica. 2012;97(2):310-7.

6. Luznik L, O'Donnell PV, Symons HJ, Chen AR, Leffell MS, Zahurak M, et al. HLAhaploidentical bone marrow transplantation for hematologic malignancies using nonmyeloablative conditioning and high-dose, posttransplantation cyclophosphamide. Biol Blood Marrow Transplant. 2008;14:6.

7. Burroughs LM, O'Donnell PV, Sandmaier BM, Storer BE, Luznik L, Symons HJ, et al. Comparison of outcomes of HLA-matched related, unrelated, or HLAhaploidentical related hematopoietic cell transplantation following nonmyeloablative conditioning for relapsed or refractory Hodgkin lymphoma. Biol Blood Marrow Transplant. 2008;14:11.

8. Raiola A, Dominietto A, Varaldo R, Ghiso A, Galaverna F, Bramanti S, et al. Unmanipulated haploidentical BMT following non-myeloablative conditioning and post-transplantation CY for advanced Hodgkin's lymphoma. Bone Marrow Transplant. 2014;49:2.

9. Gayoso J, Balsalobre P, Pascual MJ, Castilla-Llorente C, López-Corral L, Kwon $M$, et al. Busulfan-based reduced intensity conditioning regimens for haploidentical transplantation in relapsed/refractory Hodgkin lymphoma: Spanish multicenter experience. Bone Marrow Transplant. 2016;51:10.

10. Castagna L, Bramanti S, Devillier R, Sarina B, Crocchiolo R, Furst S, et al. Haploidentical transplantation with post-infusion cyclophosphamide in advanced Hodgkin lymphoma. Bone Marrow Transplant. 2017;52:683-8.

11. Ghosh N, Karmali R, Rocha V, Ahn KW, DiGilio A, Hari PN, et al. ReducedIntensity Transplantation for Lymphomas Using Haploidentical Related Donors Versus HLA-Matched Sibling Donors: A Center for International Blood and Marrow Transplant Research Analysis. J Clin Oncol. 2016;34:26.

12. Kanate AS, Mussetti A, Kharfan-Dabaja MA, Ahn KW, DiGilio A, Beitinjaneh A, et al. Reduced-intensity transplantation for lymphomas using haploidentical related donors vs HLA-matched unrelated donors. Blood. 2016;127:7.

13. Martínez C, Gayoso J, Canals C, Finel H, Peggs K, Dominietto A, et al. PostTransplantation Cyclophosphamide-Based Haploidentical Transplantation as Alternative to Matched Sibling or Unrelated Donor Transplantation for Hodgkin Lymphoma: A Registry Study of the Lymphoma Working Party of the European Society for Blood and Marrow Transplantation. J Clin Oncol. 2017;35:30.

14. Gauthier J, Poiré X, Gac AC, Leclerc M, Guillaume T, Chalandon Y, et al, Better outcome with haploidentical over HLA-matched related donors in patients with Hodgkin's lymphoma undergoing allogeneic haematopoietic cell transplantation-a study by the Francophone Society of Bone Marrow Transplantation and Cellular Therapy. Bone Marrow Transplant. 2018;53:4.

15. Ghiso A, Raiola AM, Gualandi F, Dominietto A, Varaldo R, Van Lint MT, et al. DLI after haploidentical BMT with post-transplant CY. Bone Marrow Transplant. 2015;50(1):56-61.

16. Carlo-Stella C, Ricci F, Dalto S, Mazza R, Malagola M, Patriarca F, et al. Brentuximab vedotin in patients with Hodgkin lymphoma and a failed allogeneic stem cell transplantation: results from a named patient program at four Italian centers. Oncologist. 2015;20:3.

17. Aldinucci D, Gloghini A, Pinto A, De Filippi R, Carbone A. The classical Hodgkin's lymphoma microenvironment and its role in promoting tumour growth and immune escape. J Pathol. 2010;221:3.

18. Roemer MGM, Redd RA, Cader FZ, Pak CJ, Abdelrahman S, Ouyang J, et al. Major Histocompatibility Complex Class II and Programmed Death Ligand 1 Expression Predict Outcome After Programmed Death 1 Blockade in Classic Hodgkin Lymphoma. J Clin Oncol. 2018;36:10.

19. Genadieva-Stavrik S, Boumendil A, Dreger P, Peggs K, Briones J, Corradini P, et al. Myeloablative versus reduced intensity allogeneic stem cell transplantation for relapsed/refractory Hodgkin's lymphoma in recent years: a retrospective analysis of the Lymphoma Working Party of the European Group for Blood and Marrow Transplantation. Ann Oncol. 2016;27:12.

\section{Publisher's Note}

Springer Nature remains neutral with regard to jurisdictional claims in published maps and institutional affiliations.

\section{Ready to submit your research? Choose BMC and benefit from:}

- fast, convenient online submission

- thorough peer review by experienced researchers in your field

- rapid publication on acceptance

- support for research data, including large and complex data types

- gold Open Access which fosters wider collaboration and increased citations

- maximum visibility for your research: over $100 \mathrm{M}$ website views per year

At BMC, research is always in progress.

Learn more biomedcentral.com/submissions 